Tropical Journal of Pharmaceutical Research April 2016; 15 (4): 667-677

ISSN: $1596-5996$ (print); 1596-9827 (electronic)

(C) Pharmacotherapy Group, Faculty of Pharmacy, University of Benin, Benin City, 300001 Nigeria.

All rights reserved.

Available online at http://www.tjpr.org

Original Research Article

http://dx.doi.org/10.4314/tjpr.v15i4.1

\title{
Development and optimization of fluoxetine orally disintegrating tablets using Box-Behnken design
}

\author{
Bahaa E Ali ${ }^{1,2 \star}$, Abdullah K Rabba ${ }^{3}$, Mohamed H Fayed ${ }^{1}$, Khalid M El-Say ${ }^{2,4}$, \\ Mohammad Khalid Anwer ${ }^{1}$, Mohammad Javed Ansari ${ }^{1}$, Ramadan Al-Shdefat ${ }^{1}$ \\ and Gamal A Gabr ${ }^{5,6}$ \\ ${ }^{1}$ Department of Pharmaceutics, College of Pharmacy, Prince Sattam bin Abdulaziz University, Alkharj, Kingdom of Saudi \\ Arabia, ${ }^{2}$ Department of Pharmaceutics and Industrial Pharmacy, Faculty of Pharmacy, Al-Azhar University, Cairo, Egypt, \\ ${ }^{3}$ Department of Clinical Pharmacy, College of Pharmacy, Prince Sattam bin Abdulaziz University, Alkharj, ${ }^{4}$ Department of \\ Pharmaceutics and Industrial Pharmacy, Faculty of Pharmacy, King Abdulaziz University, Jeddah, ${ }^{5}$ Department of \\ Pharmacology, College of Pharmacy, Prince Sattam bin Abdulaziz University, Alkharj, Kingdom of Saudi Arabia, ${ }^{6}$ Agricultural \\ Genetic Engineering Research Institute, Agricultural Research Center, Giza, Egypt
}

*For correspondence: Email: ali_bahaa@hotmail.com; Tel: +966 115 886043; Fax: +966 115886001

Received: 10 October 2015

Revised accepted: 19 March 2016

\begin{abstract}
Purpose: To develop and optimise some variables that influence fluoxetine orally disintegrating tablets (ODTs) formulation.

Methods: Fluoxetine ODTs tablets were prepared using direct compression method. Three-factor, 3level Box-Behnken design was used to optimize and develop fluoxetine ODT formulation. The design suggested 15 formulations of different lubricant concentration $\left(X_{1}\right)$, lubricant mixing time $\left(X_{2}\right)$, and compression force $\left(X_{3}\right)$ and then their effect was monitored on tablet weight $\left(Y_{1}\right)$, thickness $\left(Y_{2}\right)$, hardness $\left(Y_{3}\right), \%$ friability $\left(Y_{4}\right)$, and disintegration time $\left(Y_{5}\right)$.

Results: All powder blends showed acceptable flow properties, ranging from good to excellent. The disintegration time $\left(Y_{5}\right)$ was affected directly by lubricant concentration $\left(X_{1}\right)$. Lubricant mixing time $\left(X_{2}\right)$ had a direct effect on tablet thickness $\left(Y_{2}\right)$ and hardness $\left(Y_{3}\right)$, while compression force $\left(X_{3}\right)$ had a direct impact on tablet hardness $\left(Y_{3}\right)$, \% friability $\left(Y_{4}\right)$ and disintegration time $\left(Y_{5}\right)$. Accordingly, Box-Behnken design suggested an optimized formula of $0.86 \mathrm{mg}\left(X_{1}\right), 15.3 \mathrm{~min}\left(X_{2}\right)$, and $10.6 \mathrm{KN}\left(X_{3}\right)$. Finally, the prediction error percentage responses of $Y_{1}, Y_{2}, Y_{3}, Y_{4}$, and $Y_{5}$ were $0.31,0.52,2.13,3.92$ and $3.75 \%$, respectively. Formula 4 and 8 achieved $90 \%$ of drug release within the first 5 min of dissolution test.

Conclusion: Fluoxetine ODT formulation has been developed and optimized successfully using BoxBehnken design and has also been manufactured efficiently using direct compression technique.
\end{abstract}

Keywords: Box-Behnken experimental design, Orally disintegrating tablets, Direct compression, Antidepressant, Magnesium stearate, Mixing time

Tropical Journal of Pharmaceutical Research is indexed by Science Citation Index (SciSearch), Scopus, International Pharmaceutical Abstract, Chemical Abstracts, Embase, Index Copernicus, EBSCO, African Index Medicus, JournalSeek, Journal Citation Reports/Science Edition, Directory of Open Access Journals (DOAJ), African Journal Online, Bioline International, Open-J-Gate and Pharmacy Abstracts

\section{INTRODUCTION}

Up to one-third of people in all age groups have experienced swallowing issues during their lifetime [1]. The increased prevalence of swallowing issues and the development of clinically significant dysphasia (difficulty in swallowing) can be observed with increasing age, intensity of care required, and the number of diseases as well as diseases with dysphasia inducing co-morbidity [2]. ODTs greatly improve patients' compliance as it is easily taken without the need of water. It provides very rapid onset of action for patients in which it promote pregastric 
absorption of the drug molecules through buccal, sublingual, oropharyngeal, and esophageal membranes. Moreover, it avoids the first-pass hepatic metabolism leads to elevate bioavailability and reduces drug side effects [3].

Some manufacturing technologies of ODTs include direct compression, wet granulation, and lyophilization [3]. The direct compression method is the easiest and cost-effective method for the production of ODTs [4,5]. Lubrication is a critical element in tablet formulation. Lubricants are used to diminish the friction and adhesion of the powder blend to the punches and die wall [6]. Magnesium stearate is considered as the most common, chemically stable, and metallic salt boundary lubricant with high melting point, but it is hydrophobic [7]. Hence, lubricant concentration has been reported as one of the independent variables for experimental design $[5,8,9]$. In ODTs, it is important to keep quick disintegration properties of the tablets with adequate hardness [10]. Thus, optimizing the amount of magnesium stearate and mixing time is critical in the manufacturing of ODTs [5].

Optimization is a procedure that exploits available resources to obtain the best possible results. The manner of try and error that was extensively used before is now switched by the optimization system that finds a wide range of application in chemistry and pharmaceutical industry in the meantime [11]. Response surface methodology (RSM) is an assembly of mathematics and statistics procedures that is quite beneficial for the analysis and modelling of problems in which the optimized response of interest is influenced by numerous variables and objectives [12]. Box-Behnken experimental design offers 3 levels for each factor and involves a particular subsection of factorial blends from the $3 k$ factorial design $[12,13]$.

Optimization techniques have been employed by several researchers in the design and development of ODTs [14, 15]. However, some researchers had developed and prepared fluoxetine $\mathrm{HCl}$ in ODTs formulation using try and error methodology and they also used either wet granulation or sublimation techniques in order to manufacture the fluoxetine ODTs [16-18]. Consequently, this Box-Behnken experimental design will be the technique of choice to develop and optimize the fluoxetine ODTs. The design helps to develop the work methodology of fluoxetine ODTs. The design can minimize the number of trials, time, money, and gives developed formulation.
The World Health Organization has listed fluoxetine as an essential medicine [19]. Fluoxetine is a selective serotonin reuptake inhibitor indicated in the treatment of major paediatric depression, adults and children obsessive compulsion disorder, panic, premenstrual dysphoric disease, autism in adult, and trichotillomania [20,21]. The bioavailability of fluoxetine after oral administration has been reported to be up to $72 \%$, and the elimination of half-life ranged between 1 to 4 days [22]. Fluoxetine $\mathrm{HCl}$ is nominated for this work because it is widely used as antidepressant drug. In the present study, direct compression technique was used to prepare fluoxetine ODTs and Box-Behnken experimental design employed to optimize the variables, including lubricant concentration, mixing time, and compression force through investigating their impact on the tablet weight, thickness, hardness, friability (\%), and disintegration time. Moreover, the drug release profile is monitored as well.

\section{EXPERIMENTAL}

\section{Materials}

The following chemicals were obtained and used as received. Fluoxetine $\mathrm{HCl}$ was purchased from Xi'an Realin Biotechnology Co., Xi'an, China. Microcrystalline cellulose was purchased from JRS Pharma, Aalen, Germany. Lactose spray dried 250 was purchased from DFE pharma, Borculo, Netherland. Croscarmellose sodium was purchased from FMC Biopolymer, Philadelphia, USA. Magnesium stearate was purchased from Fisher Scientific, Pittsburgh, PA, USA. All chemicals and reagents used were of analytical grade.

\section{Flow properties of the powder blend}

It is very important to maintain an excellent flowability property of the powder blends to keep the filling of the punches spaces with the required amount of powder during the process of tablet compression. Therefore, after weighting and mixing the powders together before the tablet compression process took place the powder flowability should be monitored. Hausner ratio, Carr's index, and angle of repose were used to evaluate the flow properties of powders. Hausner ratio and Carr's index were evaluatedby monitoring both bulk and tapped volume of the powder $[23,24]$. Bulk density $(\mathrm{dB})$ of the designed powder formulation was calculated according to the method of Martin et al [25], while tapped density (dT) was determined according to Carr 
[23] and Sheehan [24]. Powder flowability properties were determined using Eqs 1 and 2.

Carr's index $=100(d T-d B) / d T$

Hausner ratio $=\mathrm{dB} / \mathrm{dT}$

Angle of repose was calculated using Eq 3 [24,25].

$\operatorname{Tan}(\alpha)=$ height $/ 0.5$ base

All measurements were carried out in triplicate and mean \pm standard deviation (SD) computed.

\section{Box-Behnken experimental design}

Box-Behnken experimental design (33) of the statistical package, Statgraphics $\AA$ Centurion XV, version 15.2.05 (Statpoint Technologies Inc, Warrenton, Virginia, USA), was used to assess the effects of selected independent variables on the variables responses to optimize the ODTs formulation procedure. This strategy is used to optimize the procedure using a lesser number of experimental trials by investigating quadratic response surfaces; and for the creation of second order polynomial models. The levels of factor were coded as low, medium, and high settings $(-1,0$, and +1$)[12,26]$.

Preliminary experiments revealed that the chosen independent and dependent variables along with their levels and constraints as shown in Table 1 had a significant effect on the ODTs formulation. The chosen independent variables were the percentage of lubricant concentration $\left(X_{1}\right)$, mixing time $\left(X_{2}\right)$, and compression force $\left(X_{3}\right)$. The observed responses of the dependent variables were the tablets weight $\left(Y_{1}\right)$, thickness
$\left(Y_{2}\right)$, hardness $\left(Y_{3}\right)$, \% friability $\left(Y_{4}\right)$, and in-vitro disintegration time $\left(Y_{5}\right)$. A total of 15 experimental formulae were planned by BoxBehnken design (Table 2).

A $\left(3^{3}\right)$ Box-Behnken design was employed in this work and extended to optimize the fluoxetine ODTs formulation. Through generating the polynomial equations concerning the dependent and independent variables, the procedure optimized the values of $X_{1}, X_{2}$, and $X_{3}$, which gave the best wanted possible values of $Y_{1}, Y_{2}$, $Y_{3}$, and $Y_{4}$ under controlled circumstances. $A$ new formulation was prepared according to the predicted levels of $X_{1}, X_{2}$, and $X_{3}$. Subsequently, the observed responses $\left(Y_{1}, Y_{2}, Y_{3}, Y_{4}\right.$, and $\left.Y_{5}\right)$ matched the predicted data and the residual, as well as the residual errors (\%) were then calculated.

\section{Preparation of fluoxetine HCL orally disintegrating tablets}

Tablets (300 mg) containing fluoxetine $\mathrm{HCl}$ were manufactured by direct compression method under standardized conditions, according to the formulation specified in the Box-Behnken design (Table 2). Each formulation consisted of fluoxetine $\mathrm{HCl}(6.67 \%)$, microcrystalline cellulose (30\%), croscarmellose sodium (4\%), and spray dried lactose (to $100 \%$ ) and were then mixed together for 15 min. Finally, magnesium stearate $(0.5,1$ or $1.5 \%)$ was added and mixed for 2, 13.5 and $25 \mathrm{~min}$. After that $100 \mathrm{~g}$ from each formulations powder blends were subjected to the flowability test. Additionally, the remaining formulations powder blends were pressed at 5, 10 and $15 \mathrm{KN}$ using the rotary tablet press (RoTab T, KG Pharma, Berlin, Germany).

Table 1: Independent factors with their levels and dependent variables with their constraints investigated by BoxBehnken design

\begin{tabular}{|c|c|c|c|c|c|c|}
\hline \multirow{2}{*}{ Variable } & \multirow{2}{*}{ Code } & \multirow{2}{*}{ Units } & \multicolumn{3}{|c|}{ Level } & \multirow{2}{*}{ Continuous } \\
\hline & & & $\operatorname{Low}(-1)$ & Medium (0) & High (1) & \\
\hline \multicolumn{7}{|l|}{ Independent } \\
\hline Lubricant concentration & $X_{1}$ & $\%$ & 0.5 & 1 & 1.5 & Yes \\
\hline Mixing time & $X_{2}$ & $\min$ & 2 & 13.5 & 25 & Yes \\
\hline Compression force & $X_{3}$ & $K N$ & 5 & 10 & 15 & Yes \\
\hline \multirow[t]{2}{*}{ Dependent } & \multirow{2}{*}{ Code } & \multirow{2}{*}{ Units } & \multicolumn{3}{|c|}{ Constraints (\%) } & Research \\
\hline & & & Low & Hig & & goal \\
\hline Weight & $Y_{1}$ & $m g$ & 299.1 & 319 & & $300 \pm 7.5 \%$ \\
\hline Thickness & $Y_{2}$ & $m m$ & 4.2 & 4.7 & & Minimize \\
\hline Hardness & $Y_{3}$ & $K p$ & 1.2 & 8. & & Maximize \\
\hline Friability & $Y_{4}$ & $\%$ & 0.06 & 2.5 & & Minimize \\
\hline Disintegration time & $Y_{5}$ & $\sec$ & 11.42 & 45. & & Minimize \\
\hline
\end{tabular}


Table 2: Independent variables and dependent responses employed with each designed formula

\begin{tabular}{|c|c|c|c|c|c|c|c|c|}
\hline \multirow{2}{*}{$\begin{array}{l}\text { Formula } \\
\text { code }\end{array}$} & \multicolumn{3}{|c|}{ Independent variable } & \multicolumn{5}{|c|}{ Dependent variable } \\
\hline & $X_{1}$ & $X_{2}$ & $X_{3}$ & $Y_{1}$ & $Y_{2}$ & $Y_{3}$ & $Y_{4}$ & $Y_{5}$ \\
\hline $\mathrm{F} 1$ & 1.0 & 25.0 & 15.0 & 315.5 & 4.22 & 6.3 & 0.09 & 31.01 \\
\hline $\mathrm{F} 2$ & 1.5 & 2.0 & 10.0 & 303.3 & 4.22 & 5.1 & 0.33 & 25.97 \\
\hline F3 & 1.0 & 25.0 & 5.0 & 312.1 & 4.65 & 1.3 & 2.14 & 12.42 \\
\hline F4 & 1.0 & 2.0 & 5.0 & 300.9 & 4.55 & 1.8 & 1.13 & 11.42 \\
\hline F5 & 1.5 & 13.5 & 5.0 & 319.2 & 4.73 & 1.4 & 1.96 & 12.53 \\
\hline F6 & 1.5 & 25.0 & 10.0 & 313.5 & 4.3 & 4.5 & 0.38 & 25.68 \\
\hline F7 & 0.5 & 2.0 & 10.0 & 299.1 & 4.24 & 5.3 & 0.32 & 20.07 \\
\hline F8 & 0.5 & 13.5 & 5.0 & 312.3 & 4.76 & 1.2 & 2.5 & 11.89 \\
\hline F9 & 1.0 & 2.0 & 15.0 & 300.2 & 4.08 & 8.2 & 0.06 & 40.88 \\
\hline F10 & 1.5 & 13.5 & 15.0 & 311.5 & 4.18 & 6.6 & 0.16 & 45.45 \\
\hline F11 & 0.5 & 13.5 & 15.0 & 311.1 & 4.2 & 7.3 & 0.16 & 27.98 \\
\hline F12 & 0.5 & 25.0 & 10.0 & 313.6 & 4.37 & 4.5 & 0.32 & 19.13 \\
\hline F13 & 1.0 & 13.5 & 10.0 & 308.3 & 4.29 & 4.4 & 0.19 & 22.29 \\
\hline F14 & 1.0 & 13.5 & 10.0 & 307.5 & 4.27 & 4.3 & 0.2 & 22.02 \\
\hline F15 & 1.0 & 13.5 & 10.0 & 309.2 & 4.31 & 4.5 & 0.18 & 22.78 \\
\hline
\end{tabular}

Evaluation of ODT thickness, weight variation and hardness

The thickness $(\mathrm{mm})$, uniformity of weight and hardness (20 tablets) were determined using ERWEKA Multi-Check 5.1 (ERWEKA GmbH, Heusensatamm, Germany).

\section{Tablet friability test}

Tablet friability (\%) was determined using ERWEKA, TA3R friabilator (ERWEKA $\mathrm{GmbH}$, Heusensatamm, Germany). it rotated for $4 \mathrm{~min}$ at $25 \mathrm{rpm}$.

\section{Drug content determination}

Drug content (10 Tablets) was determined according to the USP requirements. Tablets were weighed separately, crushed, and the drug was extracted with $0.1 \mathrm{~N}$ hydrochloric acid, filtered, and the content (\%) determined by Shimadzu UV-1700 spectrophotometer (Shimadzu Corporation, Kyoto, Japan) at a wavelength of $225 \mathrm{~nm}$ after suitable dilution $[3,16]$.

\section{Assessment of in vitro disintegration time}

The test was carried out in distilled water according to the USP30-NF25 requirements using a disintegration tester (ERWEKA GmbH, Heusensatamm, Germany). The apparatus was maintained at $37 \pm 2{ }^{\circ} \mathrm{C}$ [27], and the time taken for the ODT to pass through the screen or till no solid residue remains on the screen was recorded as the disintegration time.

\section{In vitro dissolution study}

In vitro dissolution was carried out according to the USP30-NF25, using an automated dissolution tester (ERWEKA, Germany) attached to an automated sampler (SP-100 peristaltic pump, Somerset, NJ, USA). Dissolution was done in $900 \mathrm{~mL}$ phosphate buffer at $\mathrm{pH}$ of $6.8 \pm$ 0.05 and $37 \pm 0.5^{\circ} \mathrm{C}$ temperature to simulate saliva fluid. The paddle rotated at $50 \mathrm{rpm}$. The samples were withdrawn automatically after 1,2 , $3,4,5,10$, and $15 \mathrm{~min}$ and were analyzed at a wavelength of $225 \mathrm{~nm}$ [28].

\section{RESULTS}

The designed fluoxetine ODTs formulations powder blends were subjected to flowability property testing, before their compression into ODTs through measuring the Hausner ratio, Carr's index, and angle of repose as displayed in Table 3. The 15 formulations powder blends displayed a flowability properties ranged from good to excellent as seen in Table 3.

ODT weight, as seen in Table 2, ranged between 299.1-319.2 $\mathrm{mg}$ with $\mathrm{F} 5$ and $\mathrm{F} 7$ respectively. All prepared ODTs were around $300 \mathrm{mg} \pm 7.5 \%$. Accordingly, all the ODT formulations met the United States pharmacopoeia requirements concerning the homogeneity of weight.

The Pareto chart (Figure 1) showed that variable $\mathrm{X}_{2}$ only extended after the reference line and the relatively larger coefficient for these terms is shown in the regression equation (Eq 4).

Therefore, only the lubricant mixing time $\left(X_{2}\right)$ had a significant effect on the tablet weight variation $\left(Y_{1}\right)$ with a positive coefficient. So, $X_{2}$ displayed a direct proportional effect on $Y_{1}$ for all formulations, although the ODT still within the USP requirements $( \pm 7.5 \%)$. Meanwhile $X_{1}$ and $X_{3}$ had an insignificant effect on $Y_{1}$ response. 
Table 3: Flowability parameters for all designed formulations

\begin{tabular}{lcccc}
\hline \multirow{2}{*}{$\begin{array}{l}\text { Formulation } \\
\text { code }\end{array}$} & \multicolumn{3}{c}{ Flowability parameter } & USP flow \\
\cline { 2 - 4 } F1 & Hausner ratio & Carr's index & Angle of repose & properties \\
\hline F1 & 1.24 & 19.57 & 30.10 & Excellent \\
F2 & 1.33 & 25.00 & 32.72 & Good \\
F3 & 1.25 & 19.79 & 30.54 & Excellent \\
F4 & 1.31 & 23.50 & 33.10 & Good \\
F5 & 1.27 & 21.54 & 29.92 & Excellent \\
F6 & 1.26 & 20.83 & 31.60 & Good \\
F7 & 1.47 & 32.18 & 35.39 & Good \\
F8 & 1.31 & 23.81 & 34.77 & Good \\
F9 & 1.33 & 25.00 & 32.41 & Good \\
F10 & 1.28 & 21.88 & 29.48 & Excellent \\
F11 & 1.30 & 23.10 & 35.14 & Good \\
F12 & 1.35 & 25.81 & 33.25 & Good \\
F13 & 1.24 & 19.44 & 30.98 & Excellent \\
F14 & 1.25 & 19.89 & 29.78 & Excellent \\
F15 & 1.24 & 19.47 & 29.92 & Excellent \\
\hline
\end{tabular}
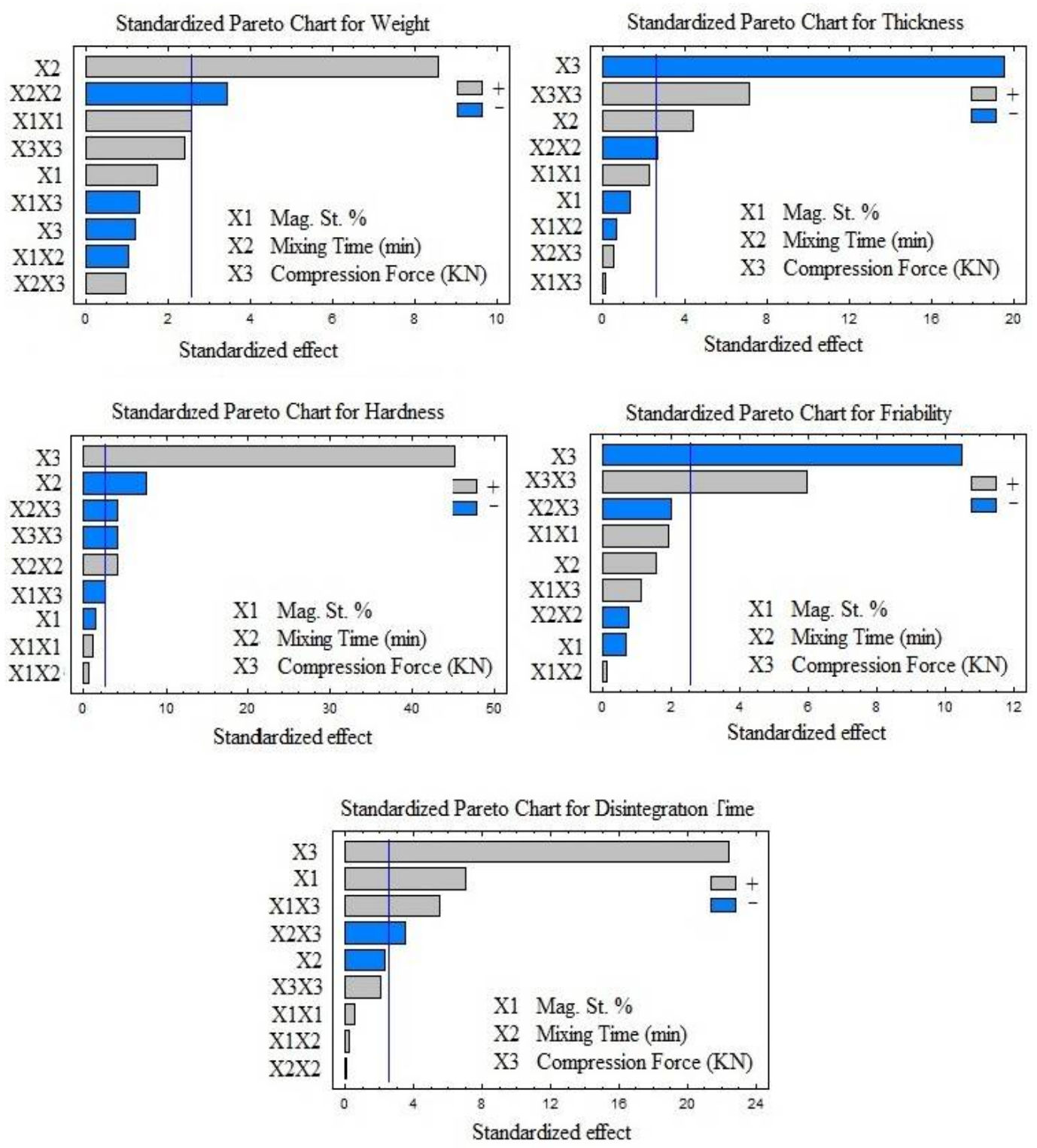

Figure 1: The Pareto charts that represent the relationship of various levels of independent factors to achieve fixed values of $Y_{1-5}$ responses 
$Y_{1}=310.962-11.9428 X_{1}+1.33677 X_{2}-$ $1.96732 X_{3}+11.2833 X_{1}^{2}-0.186957 X_{1} X_{2}-$ $0.55 X_{1} X_{3}-0.0285759 X_{2}^{2}+0.0178261 X_{2} X_{3}+$ $0.104833 x_{3}^{2}$

where $X_{1}^{2}$, quadratic term of lubricant concentration; $X_{2}^{2}$,quadratic term of mixing time; $X_{3}{ }^{2}$, quadratic term of compression force; $X_{1} X_{2}$, interaction between lubricant concentration and mixing time; $X_{1} X_{3}$, interaction between lubricant concentration and compression force; $X_{2} X_{3}$, interaction between mixing time and compression force; $Y_{1}$, tablet weight variation $(\mathrm{mg}) ; Y_{2}$, tablet thickness $(\mathrm{mm}) ; Y_{3}$, tablet hardness $(\mathrm{Kp}) ; Y_{4}$, friability $(\%)$; and $Y_{5}$, in vitro disintegration time (sec).

Table 4 and Figures $1-3$ indicate that $P_{\text {value }}$ of $X_{2}<0.05$ and the $F_{\text {ratio }}$ was 73.47 (highest value) so it had a significant effect. The $P_{\text {values }}$ of $X_{1}$ and $X_{3}$ were $>0.05$ and the $F_{\text {ratios }}$ were 3.03 and 1.45 (lowest values) so they had an insignificant effect. Moreover, fluoxetine content uniformity within all ODT formulations ranged from $97.72 \pm$ 2.97 to $103.6 \pm 1.85 \%$. Therefore, fluoxetine content distributed homogeneously throughout all suggested prepared formulations.

Tablet thickness $\left(\mathrm{Y}_{2}\right)$ measurements were displayed in Tables 2, 4 and Figures $1-3$. $\mathrm{Y}_{2}$ ranged from $4.08 \mathrm{~mm}$ to $4.76 \mathrm{~mm}$ with $\mathrm{F} 9$ and F8, respectively. Pareto chart and estimates calculated showed the priority effect of $X_{3}$ over other independent variables, the bars of $X_{3}$ and $X_{2}$ extended after the reference line accompanied with a negative coefficient of $X_{3}$ and positive coefficient of $X_{2}$. The relatively larger coefficient of these variables is seen in the regression equation for $\mathrm{Y}_{2}$ as shown below (Eq. 5):
$Y_{2}=5.40669-0.355652 X_{1}+0.015534 X_{2}-$ $0.161598 X_{3}+0.17 X_{1}^{2}-0.00217391 X_{1} X_{2}+$ $0.001 X_{1} X_{3}-0.000378072 X_{2}^{2}+0.000173913 X_{2} X_{3}$ $+0.0054 X_{3}^{2}$

Calculated $p$-values were $<0.05$, plus the $F_{\text {ratios }}$ were 19.1 and 381.14 for $X_{2}$ and $X_{3}$ respectively. Therefore, $X_{3}$ had the highest priority effect than other independent variables and accompanied by an inverse proportional effect on $Y_{2}$ while $X_{2}$ was in the second priority effect. Whereas $p$-value of $X_{1}$ was $>0.05$ and it accompanied with a very low $F_{\text {ratio }}(1.85)$. Consequently, increasing $X_{2}$ and $X_{3}$ and led to the decreasing of $Y_{2}$.

Tablet hardness responses $\left(Y_{3}\right)$ were displayed in Tables 2, 4 and Figures $1-3$. The lowest $Y_{3}$ was reported with $\mathrm{F} 8(1.2 \mathrm{Kp})$ but the highest $Y_{3}$ was reported with $\mathrm{F} 9(8.2 \mathrm{Kp})$. Additionally, the Pareto chart showed the variables of $X_{2}$ and $X_{3}$ bars were extended after the reference line and the relatively larger coefficient for these terms is shown in the regression equation as below (Eq 6).

$Y_{3}=-2.74719-0.0923913 X_{1}-0.063138 X_{2}+$ $1.02967 X_{3}+0.35 X_{1}^{2}+0.00869565 X_{1} X_{2}-$ $0.09 X_{1} X_{3}+0.00274102 X_{2}^{2}-0.00608696 X_{2} X_{3}-$ $0.0145 X_{3}^{2}$

$X_{3}$ exhibited positive coefficient while $X_{2}$ acquired negative coefficient. The $p$-values for $X_{2}$ and $X_{3}$ were $<0.05$ while $F$ ratios was 57.3 and 2044.8, respectively, indicating a significant effect of those variables on $Y_{3}$ while the calculated $P_{\text {value }}$ of $X_{1}$ was $>0.05$ and the $F_{\text {ratio }}$ was very low (1.94). Therefore, $Y_{3}$ was closely related to the increase of $X_{2}$ and $X_{3}$ [29].

Table 4: Calculated estimates, $P$-values and $F$-ratios for $Y_{1-5}$ responses

\begin{tabular}{clccccccccc}
\hline \multicolumn{2}{c}{ Response } & $\boldsymbol{X}_{\mathbf{1}}$ & $\boldsymbol{X}_{\mathbf{2}}$ & $\boldsymbol{X}_{\mathbf{3}}$ & $\boldsymbol{X}_{1}{ }^{2}$ & $\boldsymbol{X}_{\mathbf{1}} \boldsymbol{X}_{\mathbf{2}}$ & $\boldsymbol{X}_{\mathbf{1}} \boldsymbol{X}_{\mathbf{3}}$ & $\boldsymbol{X}_{\mathbf{2}}{ }^{2}$ & $\boldsymbol{X}_{\mathbf{2}} \boldsymbol{X}_{\mathbf{3}}$ & $\boldsymbol{X}_{\mathbf{3}}{ }^{2}$ \\
\hline $\boldsymbol{Y}_{\mathbf{1}}$ & Estimate & 2.6 & 12.8 & -1.8 & 5.642 & -2.15 & -2.75 & -7.558 & 2.05 & 5.242 \\
& $F_{\text {ratio }}$ & 3.03 & 73.47 & 1.45 & 6.59 & 1.04 & 1.70 & 11.82 & 0.94 & 5.69 \\
& $P_{\text {value }}$ & 0.142 & $0.0004^{*}$ & 0.282 & 0.050 & 0.355 & 0.250 & $0.019^{*}$ & 0.376 & 0.063 \\
\hline $\boldsymbol{Y}_{\mathbf{2}}$ & Estimate & -0.035 & 0.113 & -0.503 & 0.085 & -0.025 & 0.005 & -0.1 & 0.02 & 0.27 \\
& $F_{\text {ratio }}$ & 1.85 & 19.10 & 381.14 & 5.03 & 0.47 & 0.02 & 6.97 & 0.30 & 50.79 \\
& $P_{\text {value }}$ & 0.232 & $0.007^{*}$ & $0.0001^{*}$ & 0.075 & 0.523 & 0.896 & $0.046^{*}$ & 0.606 & $0.001^{*}$ \\
\hline $\boldsymbol{Y}_{\mathbf{3}}$ & Estimate & -0.175 & -0.95 & 5.675 & 0.175 & 0.1 & -0.45 & 0.725 & -0.7 & -0.725 \\
& $F_{\text {ratio }}$ & 1.94 & 57.30 & 2044.8 & 0.90 & 0.32 & 6.43 & 15.40 & 15.56 & 15.40 \\
& $P_{\text {value }}$ & 0.222 & $0.0006^{*}$ & $0.0001^{*}$ & 0.387 & 0.598 & 0.052 & $0.011^{*}$ & $0.011^{*}$ & $0.011^{*}$ \\
\hline $\boldsymbol{Y}_{\mathbf{4}}$ & Estimate & -0.117 & 0.273 & -1.815 & 0.488 & 0.025 & 0.27 & -0.193 & -0.49 & 1.5225 \\
& $F_{\text {ratio }}$ & 0.46 & 2.48 & 110.07 & 3.67 & 0.01 & 1.22 & 0.57 & 4.01 & 35.75 \\
& $P_{\text {value }}$ & 0.527 & 0.176 & $0.0001^{*}$ & 0.114 & 0.923 & 0.320 & 0.484 & 0.102 & $0.002^{*}$ \\
\hline $\boldsymbol{Y}_{\mathbf{5}}$ & Estimate & 7.64 & -2.525 & 24.265 & 0.879 & 0.325 & 8.415 & -0.181 & -5.435 & 3.319 \\
& $F_{\text {ratio }}$ & 49.83 & 5.44 & 502.69 & 0.30 & 0.05 & 30.23 & 0.01 & 12.61 & 4.34 \\
& $P_{\text {value }}$ & $0.0009^{*}$ & 0.067 & $0.0001^{*}$ & 0.605 & 0.840 & $0.002^{*}$ & 0.914 & $0.016^{*}$ & 0.092 \\
\hline
\end{tabular}

* Significant effect of factor on individual response 
Likewise, tablet friability $(\%)$ responses $\left(Y_{4}\right)$ were displayed in Tables 2 and 4 and Figures $1-3$. It ranged from $0.06-2.5 \%$ (F9 and $\mathrm{F} 8$ respectively). The $X_{3}$ had an inverse effect on $Y_{4}$ where its bar extended after the reference line and the relatively larger coefficient for this term is shown in the regression equation as below (Eq. 7):

$Y_{4}=5.84405-2.63685 X_{1}+0.0719329 X_{2}-$ $0.786978 X_{3}+0.975 X_{1}^{2}+0.00217391 X_{1} X_{2}+$ $0.054 X_{1} X_{3}-0.000727788 X_{2}^{2}-0.00426087 X_{2} X_{3}+$ $0.03045 X_{3}^{2}$

However, $X_{1}$ and $X_{2}$ had an insignificant effect on $Y_{4}$ response. Furthermore, the $P_{\text {values }}$ were $<0.05$ and the $F_{\text {ratio }}(110.07)$ were the highest among all other variables effect. On the other hand, the $P_{\text {values }}$ for $X_{1}$ and $X_{2}$ were $>0.05$ and the $F_{\text {ratios }}$ were 0.46 and 2.48 respectively, which were lower than the value of $X_{3}$ (110.07) reported. This indicated that $X_{1}$ and $X_{2}$ had insignificant and low priority effect on $Y_{4}$. Therefore, the tablets that were prepared at stronger $X_{3}$ presented lower $Y_{4}$ due to the hardness and thickness [29].

The time of disintegration $\left(Y_{5}\right)$ responses were seen in Tables 2, 4 and Figures 1 - 3. F4 exhibited the lowest $Y_{5}(11.42 \mathrm{~s})$ but the highest was noticed with F10 (45.45 s) in which the $Y_{5}$ regression equation (Eq. 8 ):

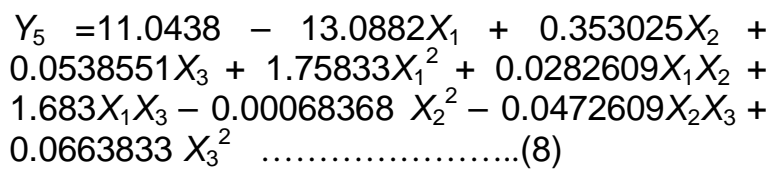

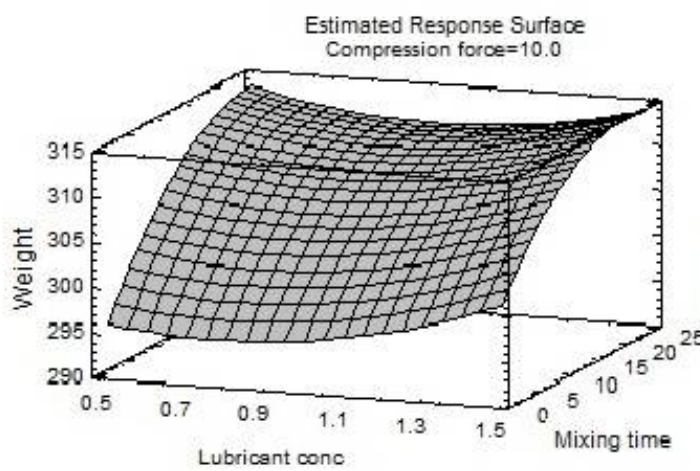
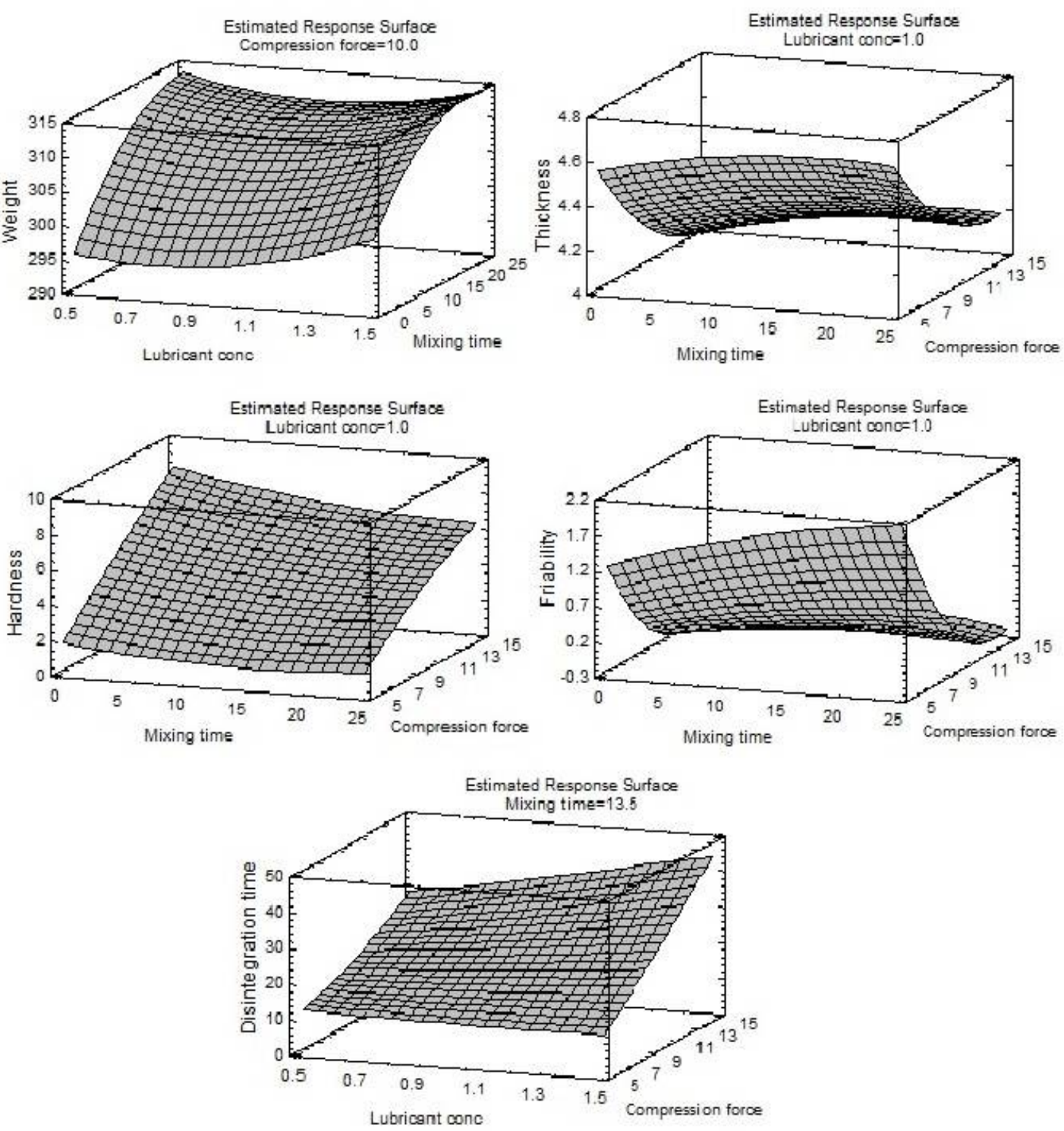

Figure 2: 3D response surface plots represent the relationship of different levels of independent factors to achieve the fixed values of $Y_{1-5}$ responses 

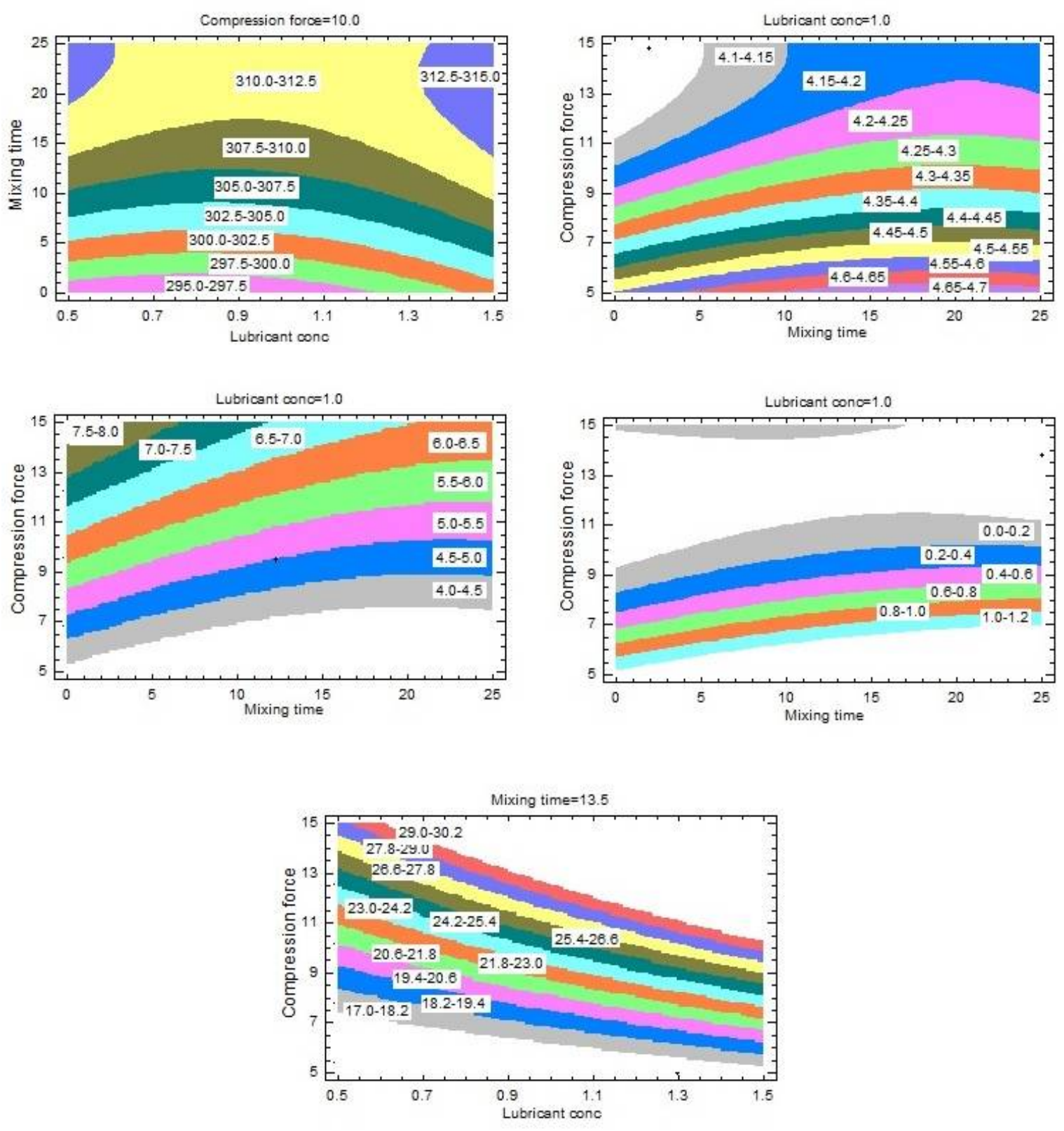

Figure 3: Contours surface response plots represent the relationship of different levels of independent factors to achieve the fixed values of $Y_{1-5}$ responses

The positive coefficient of $X_{1}$ and $X_{3}$ demonstrated direct proportional effect plus high priority effect of $X_{3}$ compared to $X_{1}$ on $Y_{5}$ as displayed. The $P_{\text {values }}$ of $X_{1}$ and $X_{3}$ were $<0.05$. The $P_{\text {value }}$ of $X_{2}$ was $>0.05$ which indicated an insignificant effect on $Y_{5}$. Additionally, the $F_{\text {ratios }}$ of $X_{1}, X_{2}$, and $X_{3}$ were $49.83,5.44$, and 502.69 respectively. These results are in accordance with the findings of other works [29].

All formulations achieved $\mathrm{T}_{50}$ (time of $50 \%$ of fluoxetine release) within the first minute while $\mathrm{T}_{80}$ (time of $80 \%$ of fluoxetine release) was achieved by F4 and F8 within $1 \mathrm{~min}$. The dissolution of the 15 formulations after $5 \mathrm{~min}$ ranged from $71.45-96.73 \%$. After $10 \mathrm{~min}$, the values ranged from $78.56-100.00 \%$; while after $15 \mathrm{~min}$, dissolution from almost all formulations approximately $100 \%$. Figure 4 showed the dissolution profile of selected formulations. This selection is based on the fact that these selected formulations showed the effect of $X_{1}, X_{2}$, and $X_{3}$ employed without repeating the results for the remaining formulations that display the effect of independent variables.

\section{DISCUSSION}

The powder blends displayed acceptable flowability property which ranged from good to 


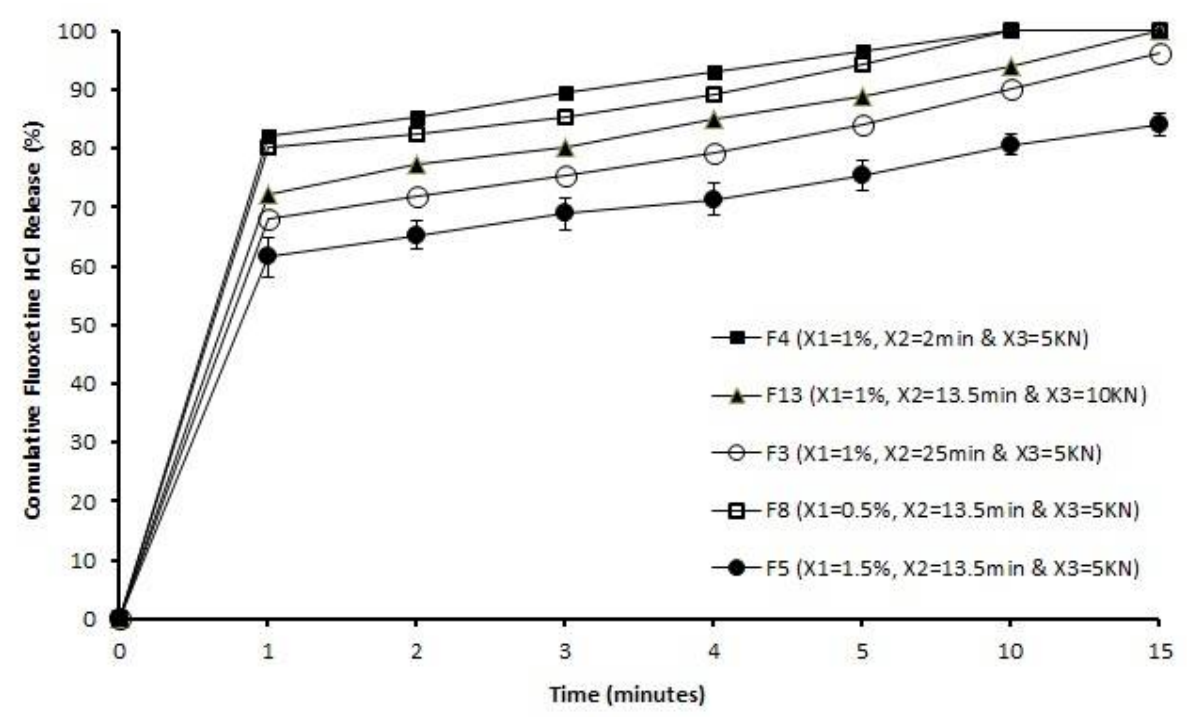

Figure 4: Dissolution profiles for some selected formulations

excellent $[23,24]$. Magnesium stearate particles formed a thin layer covering the other powder particles that improved the powder flowability properties, especially with higher concentration $(1.5 \%)$. The longer mixing time (13.5 and 25 min) enabled the lubricant particles to fill all groves over the powder blend particles surface and form an intact thin layer over the particles surfaces [9].

Tablet weight variation is closely correlated with the increase of lubricant mixing time due to the presence of lubricant material like magnesium stearate within the powder blend. Besides, the mixing time allowed the lubricant particles to spread efficiently throughout the tablet ingredients particles forming a thin layer over these particles, that leads to minimum particles interaction and friction and consequently improving the flowability properties [7]. The punches spaces of tablet press machine were filled with powder particles without pressure only with the powder flowability effect. Therefore, excellent powder flowability property is considered as a requirement for the successful direct compression technique [9]. Excellent powder flowability property reduced the particle friction so particles moved easily over each other. So, the particle-particle spaces might be reduced to its minimum, leaving more spaces that could be filled with excess particles between the punches spaces instead of air that might explain the tablet weight increase. At the same time the ODTs weight is controlled by the punches spaces that were adjusted before commencing the compression process. Consequently, the ODTs weights were not very noticeable, but they were around $300 \mathrm{mg} \pm 7.5 \%$ [24].
Tablets thickness is mainly influenced by the increase in compression force and the decrease of mixing time since the decrease of powder flowability property leads to the decrease of particles content. Tablet hardness is also strictly associated with the increase of compression force and the decrease of mixing time as reported by Andries et al [29]. Tablet friability is affected by the compression force employed during tablets pressing in which leads to harder tablets. Disintegration time is thoroughly related to the increase in lubricant concentration and compression force, but it is not influenced by the length of mixing time. It might be due to the decrease of tablets friability \% and hardness as reported tby others [29].

Fluoxetine tablet content was uniformly distributed throughout the formulation and the direct compression technique displayed an efficient procedure for the manufacturing of fluoxetine $\mathrm{HCl}$ ODTs.

The fluoxetine release (\%) was very high within the first minute of dissolution, then $\mathrm{T}_{80}$ was noticed within $5 \mathrm{~min}$ of dissolution with those formulations that had the smallest lubricant concentration, shortest mixing time, and lowest compression force (Figure 4). Consequently, lubricant concentration, mixing time, and compression force influenced the fluoxetine release (\%) due to the hydrophobic property of magnesium stearate, since it forms a layer over the particulates and stronger compression force increases the tablets hardness as reported by others [29].

The goal of this work was to prepare an optimized fluoxetine ODTs formula with an average weight of $300 \mathrm{mg} \pm 7.5 \%$, minimum 
Table 5: The suggested optimum formula plus predicted, observed responses, residuals and prediction error \%

\begin{tabular}{ccccccc}
\hline $\begin{array}{l}\text { Independent } \\
\text { Factors }\end{array}$ & Optimum & $\begin{array}{l}\text { Dependent } \\
\text { Factors }\end{array}$ & Predicted & Observed & Residuals & $\begin{array}{c}\text { Prediction } \\
\text { Error (\%) }\end{array}$ \\
\hline$X_{1}$ & 0.86 & $Y_{1}$ & 309.15 & 308.2 & 0.95 & 0.31 \\
$X_{2}$ & 15.3 & $Y_{2}$ & 4.28 & 4.3 & -0.02 & -0.4 \\
$X_{3}$ & 10.6 & $Y_{3}$ & 4.7 & 4.6 & 0.1 & 2.13 \\
& & $Y_{4}$ & 0.135 & 0.129 & 0.006 & 4.44 \\
& & $Y_{5}$ & 22.4 & 21.6 & 0.8 & 3.57 \\
\hline
\end{tabular}

tablet thickness, friability (\%), and disintegration time, but accompanied with maximum tablet hardness. The optimum responses of the variables were gained through graphical and numerical analysis by means of statistical Statgraphics $\AA$ software and based on the principle of desirability [30]. The Box-Behnken design has suggested an optimized formula as in Table 5.

Therefore, the suggested formula was prepared and then characterized as done before. The experimental results were compared to the design predicted results by calculating the residual and residual error (\%) in order to validate the Box-Behnken design suggestion. The residual differences were $0.95 \mathrm{mg},-0.02$ $\mathrm{mm}, 0.1 \mathrm{Kp}, 0.006 \%$, and $0.8 \mathrm{~s}$ respectively, and the prediction errors (\%) were $0.31,-0.4,2.13$, 4.44, and $3.57 \%$, respectively. The results showed an insignificant difference (t-test, $\mathrm{P}_{\text {value }}>$ 0.05 ) between the predicted and experimental responses (Table 5). The suggested optimal formula showed the best-fitted formula amongst other formulae according to the prediction error (\%) and/or residual results which were below $5 \%$ and could be considered negligible.

\section{CONCLUSION}

Fluoxetine ODTs have been successfully developed and improved by a Box-Behnken experimental design, and prepared using direct compression technique. Variables including lubricant concentration, mixing time, and compression force have a quantitative effect on the weight variation, thickness, hardness, friability (\%), and in vitro disintegration time which could be predicted by Box-Behnken design.

The experimental values of the improved formula were close and in line with the predicted values that verified the integrity of the developed fluoxetine ODTs formulation. Finally, this optimized and developed antidepressant drug, fluoxetine $\mathrm{HCl}$, ODTs formulation will achieve numerous targeted benefits such as rapid onset of action, high bioavailability, ease of administration, and patients' convenience, especially for those with swallowing difficulties regardless of age.

\section{ACKNOWLEDGEMENT}

The authors acknowledge the support of Professor Fars Al Anazy, and also Mr Haitham F Mostafa from Kayyali Research Chair for Pharmaceutical Industries for providing access to laboratory facilities at College of Pharmacy, King Saud University, Riyadh, Kingdom of Saudi Arabia.

\section{REFERENCES}

1. Eslick GD, Talley NJ. Dysphagia: epidemiology, risk factors and impact on quality of life--a population-based study. Aliment Pharmacol Ther 2008; 27: 971-979. doi: 10.1111/j.1365-2036.2008.03664.x

2. Chen PH, Golub JS, Hapner ER, Johns MM. Prevalence of perceived dysphagia and quality-of-life impairment in a geriatric population. Dysphagia 2009; 2: 1-6. doi: 10.1007/s00455-008-9156-1

3. Fu Y, Yang S, Jeong SH, Kimura S, Park K. Orally fast disintegrating tablets: developments, technologies, taste-masking and clinical studies. Crit Rev Ther Drug Carrier Syst 2004; 21: 433-475. doi: 10.1615/CritRevTherDrugCarrierSyst.v21.i6.10

4. Mostafa HF, Ibrahim MA, Sakr A. Development and optimization of dextromethorphan hydrobromide oral disintegrating tablets: effect of formulation and process variables. Pharm Dev Technol 2013; 18: 454-463. doi: 10.3109/10837450.2012.710237.

5. Late SG, Yu Y-Y, Banga AK. Effects of disintegrationpromoting agent, lubricants and moisture treatment on optimized fast disintegrating tablets. Int $J$ Pharm 2009;365: 4-11. doi: 10.1016/j.ijpharm.2008.08.010.

6. Miller TA, York P. Pharmaceutical tablet lubrication. Int $J$ Pharm 1988; 41: 1-19. doi: 10.1016/03785173(88)90130-5.

7. Perrault $M$, Bertrand F, Chaouki J. An investigation of magnesium stearate mixing in a $v$-blender through gamma-ray detection. Powder Technol 2010; 200: 234245. doi: 10.1016/j.powtec.2010.02.030.

8. Fassihi RA, Mcphillips AM, Uraizee SA et al. Potential use of magnesium stearate and talc as dissolution retardants in the development of controlled drug delivery systems. Pharm Ind 1994; 56: 579-583. 
9. Morin G, Briens L. The effect of lubricants on powder flowability for pharmaceutical application. AAPS Pharm Sci Tech 2013; 14: 1158-1168. doi: 10.1208/s12249013-0007-5.

10. Kuno Y, Kojima M, Nakagami H, Yonemochi E, Terada K. effect of the type of lubricant on the characteristics of orally disintegrating tablets manufactured using the phase transition of sugar alcohol. Eur $J$ Pharm Biopharm 2008; 77: 986-992. doi:10.1016/j.ejpb.2008.02.016.

11. Bonadeo D, Ciccarello F, Pagano A. Process for the preparation of a granulate suitable to the preparation of rapidly disintegrable mouth-soluble tablets and compositions obtained theraby, U.S. Patent 6,149,938, November 21, 2000.

12. Montgomery DC. Design and analysis of experiments. John Wiley \& Sons; 2008. $680 p$.

13. Khuri Al, Mukhopadhyay S. Response surface methodology. Wiley Interdiscip Rev Comput Stat 2010; 2: 128-149. doi:10.1002/wics.73

14. Huang $Y$-B, Tsai $Y-H$, Lee $S-H$, Chang J-S, Wu P-C. Optimization of $\mathrm{pH}$-independent release of nicardipine hydrochloride extended-release matrix tablets using response surface methodology. Int J Pharm 2005; 289: 87-95. doi:10.1016/j.jpharm.2004.10.02.

15. El-Say kM, El-Helw A-R, Ahmed OA, Hosney KM, Ahmed $T A$, Kharshoum RM et al. Statistical optimization of controlled release microspheres containing cetirizine hydrochloride as a model for water soluble drugs. Pharm Dev Technol 2014; 7450: 1-9. doi: 10.3109/10837450.2014.920353

16. Indhumathi D, Prabha KS. Formulation and evaluation of orodissolving tablet of fluoxetine using superdisintegrants. IJPBS 2011; 2: 833-847.

17. Kumar AA, Kumar AA, Sudheer $B$, Swathi K, Vijaya $M$, Reddy R. Comparison study of effect of superdisintegrants on formulation and evaluation of fluoxetine hydrochloride orodispersible tablets by wet granulation and sublimation method. AJADD 2014; 2: 52-61.

18. Indhumathi $D$, Grace $R$. Design and optimization of orodissolving tablet of antidepressant drug by superdisintegrants addition method. Int $J$ Pharm Sci Rev Res 2010; 2: 1-9.

19. WHO. WHO model list of essential medicines: 18th List. 2013; [cited 2015 April 23]. Available from http://www.who.int/medicines/publications/essentialmedi cines/en/index.html
20. Benvenuto A, Battan B, Porfirio MC, Curatolo $P$. Pharmacotherapy of autism spectrum disorders. Brain Dev 2013; 35: 119-127. doi: 10.1016/j.braindev.2012.03.015

21. Williams $K$, Brignell A, Randall M, Silove N, Hazel IP. Selective serotonin reuptake inhibitors (SSRIs) for autism spectrum disorders (ASD) (review). Cochrane Database Syst Rev 2013; 1-39. doi: 10.1002/14651858.CD004677.pub2

22. Altamura AC, Moro AR, Percudani M. Clinical pharmacokinetics of fluoxetine. Clin Pharmacokinet 1994; 26: 201-214. doi: 10.2165/00003088-19942603000004.

23. Carr R. Evaluating flow properties of solids. Chem Eng 1965; 72: 163.

24. Sheehan C. General chapters: <1174> Powder flow; [cited 2015 April 23]. Available from: http://www.pharma copeia.cn/v29240/usp29nf24so_c1174.html

25. Martin A, Bustamante P, Chun AHC. Micromeritics in physical pharmacy; physical chemical principles in the pharmaceutical sciences; Mundorff GH (ed). Lippincott Williams \& Wilkins, Baltimore, Maryland, USA: Philadelphia, Pennsylvania, USA; 1993; pp 423-452.

26. Karnachi AA, Khan MA. Box-Behnken design for the optimization of formulation variables of indomethacin coprecipitates with polymer mixtures. Int J Pharm 1996; 131: 9-17. doi:10.1016/0378-5173(95)04216-4

27. US.FDA/CDER. Guidance for industry orally disintegrating tablets. 2007; [cited 2015 April 23]. Available from: http://www.fda.gov/downloads/Drugs/ GuidanceComplianceRegulatoryInformation/Guidances/ ucm070578.pdf

28. Weitschies W, Wilson CG. In vivo imaging of drug delivery systems in the gastrointestinal tract. Int J Pharm 2011; 417: 216-226. doi: 10.1016/j.ijpharm.2011.07.031

29. Marais AF, Song $M$; De Villiers MM. Effect of compression force, humidity and disintegrant concentration on the disintegration and dissolution of directly compressed furosemide tablets using croscarmellose sodium as disintegrant. Trop $J$ Pharm Res 2003; 2: 125-135.

30. Mujtaba A, Ali M, Kohli K. Statistical optimization and characterization of $\mathrm{pH}$-independent extended-release drug delivery of cefpodoxime proxetil using BoxBehnken design. Chem Eng Res Des 2014; 92: 156165. doi: 10.1016/j.cherd.2013.05.032. 